\title{
CORRIGENDUM
}

\section{Cell type-specific regulation of distinct sets of gene targets by Pax3 and Pax3/FKHR}

\author{
S Begum, N Emami, A Cheung, O Wilkins, S Der and PA Hamel
}

Oncogene (2008) 27, 1812; doi:10.1038/onc.2008.12

Correction to: Oncogene (2005) 24, 1860-1872; doi:10.1038/sj.onc.1208315; published online 31 January 2005
Since the publication of the above manuscript, the authors have identified an error in the author list; the name of the second author was misspelt. The corrected author list is shown above.

\section{ERRATUM}

\section{Functional characterization of TIP60 sumoylation in UV-irradiated DNA damage response}

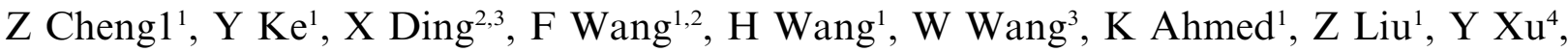

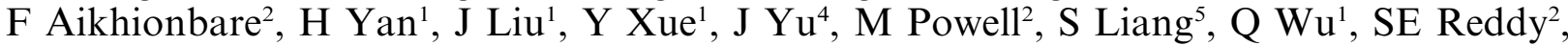

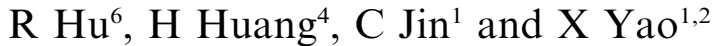

\begin{abstract}
${ }^{1}$ Laboratory of Cellular Dynamics, Hefei National Laboratory and University of Science \& Technology, Hefei, China; ${ }^{2}$ Cancer Biology Program, Morehouse School of Medicine, Atlanta, GA, USA; ${ }^{3}$ Department of Medicine, Beijing University of Chinese Medicine, Beijing, China; ${ }^{4}$ Department of Hematology, The $1^{\text {st }}$ Affiliated Hospital, Zhejiang University, Hongzhou, China; ${ }^{5}$ MOE Key Laboratory of Protein Chemistry, Hunan Normal University, Changsha, China and ${ }^{6}$ Department of Endocrinology \& Metabolism, Fudan University School of Medicine, Shanghai, China
\end{abstract}

Oncogene (2008) 27, 1812; doi:10.1038/onc.2008.11

Correction to: Oncogene (2008) 27, 931-941; doi:10.1038/ sj.onc.1210710; published online 20 August 2007

Owing to typesetting errors, three authors were omitted from the author list. The corrected list and affiliations is shown on this page, along with extended acknowledgements as follows:

\section{Acknowledgements}

This work was supported by grants from Chinese 973 project (2002CB713700, 2007CB914503, and
2006CBOF0503), Chinese Academy of Sciences (KSCX1-YW-R65 and KSCX2-YW-H10), Chinese 863 project (2001AA215331), Chinese Ministry of Education (20020358051; 20050358061 and IRT0413 to XD), Chinese Natural Science Foundation (39925018, 30270654, 90508002, 30121001 and 30500183 to XD), American Cancer Society (RPG-99-173-01), National Institutes of Health (DK56292, CA89019, and CA92080) and a GCC Breast Cancer Research Grant to $\mathrm{XY}$. The facilities were supported in part by NIH/NCRR/RCM1 Grant G-12-RR03034. SER and $\mathrm{XY}$ are GCC eminent scholars. 